\title{
AS INTERAÇÕES ENTRE INIQUIDADES DE GÊNERO E A INEFETIVIDADE DOS DIREITOS SOCIAIS EM TEMPOS DE AUSTERIDADE
}

\author{
Mirela Faleiros Rezende ${ }^{1}$ \\ Carolina Lima Gonçalves ${ }^{2}$
}

\section{Resumo}

O presente trabalho parte da premissa de que a política fiscal é o ponto decisivo do Estado democrático capitalista, isto é, o exame das fontes de arrecadação tributária e a definição da alocação de tais recursos proporciona a compreensão realística do Estado -- inclusive de seus aspectos culturais e sociais. Partindo da premissa de que o pacote da austeridade pode reduzir direitos sociais, a presente pesquisa busca verificar a efetividade dos direitos constitucionalmente assegurados em tempos de austeridade. Para tanto, inicia-se pelo reconhecimento de que todos os direitos implicam um custo estatal para sua implementação. Evidenciando que a alocação de recursos, pelo Estado, compreende despesas públicas, tributação e concessão subsídios fiscais. Desse modo, indicam a aplicação de um programa de governo e revelam suas escolhas e prioridades. Logo após, passa-se ao exame da austeridade, sua estrutura, acoplamentos, fundamentos e objetivos. Por fim, examina-se em que medida o ajuste fiscal aplicado no Brasil se relaciona iniquidades de gênero, verificando seus impactos, no Brasil atual.

Palavras-chave: Austeridade, Política fiscal, Paridade de gênero.

\begin{abstract}
This paper starts from the premise that fiscal policy is a decisive point of the democratic capitalist State, that is, the examination of tax collection sources and the definition of the allocation of such resources, provides a realistic understanding of the State - including its cultural and social aspects. Based on the premise that the austerity package can reduce social rights, this research seeks to verify the effectiveness of constitutionally guaranteed rights in times of austerity. Therefore, it begins with the recognition that all rights entail a cost to their implementation, evidencing that the allocation of resources by the State, public expenditures, taxation or granting tax subsidies, indicates the application. Evidencing that the allocation of resources, by the State, includes public expenses, taxation and tax subsidies. In this way, they indicate the implementation of a government program and reveal their choices and priorities. Soon, goes to the examination of austerity, its structure, couplings, fundamentals and objectives. Finally, we examine the extent to which the fiscal adjustment applied in Brazil relates to gender inequalities in present-day Brazil.
\end{abstract}

Keywords: Austerity, Fiscal policy, Gender parity.

\section{Resume}

Este documento asume que la política fiscal es el punto de inflexión del estado democrático capitalista, es decir, el examen de las fuentes de ingresos fiscales y la definición de la asignación de dichos recursos

\footnotetext{
${ }^{1}$ Graduada em Direito pela PUC-GO, mestranda em Direitos Humanos pela UFG, e-mail para contato: mfr.13@hotmail.com.

2 Graduada em Direito, mestranda em Direitos Humanos pela UFG, e-mail para contato: carolina.lima.goncalves@ hotmail.com.
} 
proporciona una comprensión realista del estado, incluyendo sus aspectos culturales y sociales. Basado en la premisa de que el paquete de austeridad puede reducir los derechos sociales, esta investigación busca verificar la efectividad de los derechos constitucionalmente garantizados en tiempos de austeridad. Con este fin, comienza con el reconocimiento de que todos los derechos conllevan un costo estatal para su implementación. Evidenciando que la asignación de recursos, por parte del Estado, incluye gastos públicos, impuestos y subsidios fiscales. De esta manera, indican la implementación de un programa de gobierno y revelan sus elecciones y prioridades. Poco después, examinamos la austeridad, su estructura, acoplamientos, fundamentos y objetivos. Finalmente, examinamos en qué medida el ajuste fiscal aplicado en Brasil relaciona las desigualdades de género, verificando sus impactos en el Brasil actual.

Palabras-clave: Austeridad, Política fiscal, Paridad de género.

\section{INTRODUÇÃO}

Para os fins da presente pesquisa, consideramos tempos de austeridade o momento

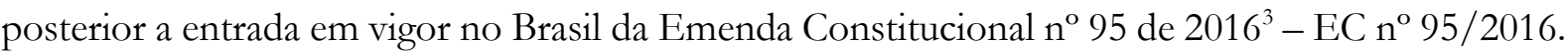
Embora seja possível defender outros momentos de recessão e rigidez do gasto público destinado aos direitos sociais, não há no direito brasileiro nenhum precedente de retenção de investimentos comparáveis em alcance e gravidade à austeridade conferida pela Emenda ora em comento. Dentre os aspectos mais sérios que implicam relevância ao estudo da EC n ${ }^{\circ} 95 / 2016$, e que permitem afirmar que a mesma marca um novo e específico tempo de austeridade, encontram-se: a) o alcance; b) a temporalidade; c) a rigidez instrumento normativo; d) a indiferença em relação ao crescimento econômico; e) impacto nos direitos sociais.

É possível, assim, falar em era da austeridade a partir da EC nº5/2016, pois a mesma: a) afeta diretamente as despesas primárias - aquelas sem relação com os juros e a dívida pública, a exemplo de despesas de pessoal, de manutenção, de investimento, dentre outras; b) vigerá por um período de 20 anos; c) foi implementada por meio de Emenda à Constituição Federal (CF), o que configura maior complexidade do processo legislativo para sua alteração; d) não traz qualquer alteração em função de eventual crescimento econômico que ultrapasse os gastos dantes previstos; e) institui restrição na verba destinada ao orçamento da União para saúde e educação, que passou a sujeitar-se apenas à correção monetária, isto é, manterá o que foi definido na previsão orçamentária anterior, independentemente dos eventos reais que criem novas demandas para efetivação de tais direitos (envelhecimento da população e surto de doenças, por exemplo).

A partir dessas constatações, o presente trabalho analisa os efeitos da EC n ${ }^{\circ}$ 95/2016 sob a perspectiva sustentada pela Sociologia Fiscal (SCHUMPETER, 1991), de que a fiscalidade -

\footnotetext{
${ }^{3}$ O conjunto de medidas trazidas pela Emenda Constitucional no 95 de 2016 inaugurou o chamado Novo Regime Fiscal.
} 
tributação e orçamentação pública - revelam fatores estruturais da sociedade, permitindo uma compreensão agudizada de certos fenômenos sociais. Isso dito, a presente pesquisa analisa as interações entre iniquidades de gênero a inefetividade dos direitos sociais em tempos de austeridade. Para tanto, esta pesquisa parte da premissa de que os direitos humano/fundamentais demandam custos para sua efetivação ${ }^{4}$, de modo que a orçamentação, isto é, alocação de recursos para atender as necessidades dos cidadãos relevam as prioridades e disposição do Estado em conferir efetividade a certos direitos, bem como, em que medida tais direitos afetam as iniquidades de gênero, uma vez que o machismo estrutural é latente em nossa sociedade contemporânea e, pode ser sensivelmente afetado pelo orçamento.

A plena realização dos direitos deve considerar a existência de um orçamento limitado, ou seja, os recursos financeiros são escassos. O fato de os recursos serem limitados se apresenta como um dos fatores que contribuem para que os direitos não sejam absolutos. É preciso alocar os recursos levando em conta sua escassez, desse modo, há a necessidade de que sejam feitos acordos para que se decida: como, quando e qual parcela desses recursos será destinado e para a execução de determinados direitos. Esses arranjos são, assim, inevitáveis (HOLMES \& SUSTEIN, 2000). O Brasil é um país estruturalmente machista e racista, em que as mulheres encontram-se em situação de vulnerabilidade. Assim, os direitos delas quase nunca são priorizados, e esses arranjos nem sempre são capazes de promover a paridade de gênero. Em tempos de austeridade, em que os recursos são ainda mais escassos e os direitos sociais estão gravemente ameaçados, os direitos das mulheres estão particularmente em risco.

\section{A QUESTÃO DO CUSTO DOS DIREITOS SOCIAIS}

Para compreender as políticas públicas que visam conferir efetividade aos direitos sociais, faz-se necessário o exame da clássica concepção dos direitos humano-fundamentais que os segregam entre direitos prestacionais e não-prestacionais, com vistas a analisar como tal perspectiva influencia na efetividade dos chamados direitos sociais ou prestacionais, para tanto, importa apresentar a teoria das dimensões dos direitos humano-fundamentais difundida por (BOBBIO, 2004), a qual é criticada por diversos autores, tais como Rabossi (1993), Holmes \& Sustein (2000) e Galdino (2005).

\footnotetext{
${ }^{4}$ Importa mencionar que todos os direitos demandam custo para sua efetivação como reiteram Holmes e Sustein (2000), uma vez que não basta a mera previsão formal para sua efetividade, sendo necessária no mínimo uma estruturação estatal a fim de garantir e conferir efetividade a todos os direitos.
} 
Segundo tal categorização, é possível proceder ao exame dos direitos humanos centrando em quatro vieses (RAMOS, 2016, p. 29): a) direito - pretensão; b) direito-liberdade; c) direito-poder; d) direito-imunidade. Afirma-se que há direitos humanos que materialização a possibilidade de exigir uma prestação de um terceiro, via de regra do Estado, sendo estes os chamados prestacionais. Por outro lado, há direitos humanos que consubstanciam um direito de não interferência de terceiros, com ênfase novamente na figura do Estado, isto é, tal categoria de direito gera em outro polo uma ausência de direitos, direitos de liberdade. Já o direito como poder, seria aquele direito que, quando exercido, imputa uma sujeição a quem se dirige. E por fim, o direito-imunidade consiste na possibilidade conferida a uma pessoa de agir sem que terceiro possa imputar consequências a essa ação.

Desse modo, para os fins da pesquisa pretendida, faz-se necessário examinar em que medida a concepção canônica ${ }^{5}$ dos diretos humanos fundamentais afeta a efetividade dos direitos denominados sociais/prestacionais, a fim de a examinar especificamente o impacto dessa teoria na efetividade dos direitos sociais, vez que, a mesma fundamenta a política de austeridade fiscal. No mesmo sentido, ante a dimensão polissêmica dos termos positivos e negativo, enfatiza Flávio Galdino que:

A dicotomia positivo/negativo diz respeito a duas situações interligadas, a saber: (i) a necessidade ou não de prestação estatal (em caso negativo ter-se-ia mera omissão) para consecução de direitos fundamentais, de modo que a expressão direitos positivos referese em especial, a direitos que demandam prestação estatal para sua efetivação e, (ii) em estreita correlação, os custos que essas prestações ocasionam para o Estado, de forma que positividade refere-se também a dispêndio de recursos. (GALDINO, 2005, p. 151)

É nessa perspectiva que, tanto Rabossi (1993) quanto Galdino (2005) rechaçam a ideia de que há direitos humano-fundamentais naturalmente distintos, sendo que uns não exigem prestações estatais para sua plena aplicação, portanto, são os direitos humanos autênticos, enquanto outros, por dependerem de uma conduta positiva dos Estados (ação), encontram-se a mercê das possibilidades econômicas para sua prestação. Desse modo, a distinção clássica dos direitos humano-fundamentais como prestacionais (positivos) e não-prestacionais (negativos) englobam a ideia de que os direitos humano-fundamentais envolvem as relações jurídicas dos particulares frente ao Estado, bem como consideram o aspecto do custo do agir estatal e se alicerçam no discurso da genealogia e evolução da positivação dos direitos humanos no âmbito internacional.

\footnotetext{
${ }^{5}$ Importa observar que como concepção canônica entende-se a perspectiva amplamente disseminada de dicotomia natural dos direitos humanos em direitos civis e não prestacionais (negativos) e direitos econômicos e prestacionais (positivos) (RABOSSI, 1993, p. 45).
} 
A fim de refutar a concepção canônica dos direitos humanos e descortinar as questões ideológicas nas quais tal teoria se alicerça, Rabossi (1993) examina a positivação dos direitos humanos no âmbito internacional demonstrando as origens da ideia de que violar direitos humanos relacionados à subsistência não pode ser compreendida com uma falta grave passível de punição dos Estados, vejamos:

\begin{abstract}
La concepción canônica encuentra apoyo en el sistema normativo internacional; tiene um claro origen ideológico y se escuda en argumentos técnicos que exhiben um grado de sofistifcación nada depreciable. Um conjunto de "fuentes" tan peculiar há producido efectos importantes: La concepción canônica está prepupuestada en la teorización estándar de los derechos humanos y es um esteriotipo recurrente, no solo em los âmbitos especializados, sino em la manera "popular" de visualizar y valorar los derechos humanos. (RABOSSI, 1993, p. 46) ${ }^{6}$.
\end{abstract}

Por sua vez, Galdino (2005) ressalta a relevância da distinção entre direitos humanofundamentais positivos e negativos em razão de tal dicotomia orientar duas concepções tanto no âmbito teórico quanto na seara prática, qual seja “(i) no plano teórico, o da formulação de uma linha evolutiva dos Estados contemporâneos, do Liberal ao Social; e (ii) no plano prático, da distribuição de recursos escassos em relação ao atendimento de direitos fundamentais." (GALDINO, 2005, p. 163).

Insta mencionar que tanto Rabossi (1993), por meio do exame da genealogia da positividade normativa dos direitos humanos na seara internacional, quanto Galdino (2005), quando da análise dos discursos erigidos sob a dicotomia entre direitos fundamentais negativos e positivos, convergem para a mitigação das teorias que alicerçam a menor efetividade dos direitos sociais. Em síntese, enquanto Rabossi (1993) revela os estereótipos e ideologias que albergam a impossibilidade de exigência de cumprimento dos direitos básicos de subsistência e consequente punição do Estado violador, Galdino ${ }^{7}$ (2005) denuncia que, em verdade, todos os direitos custam, pois todos em alguma medida exigem uma atuação do Estado a fim de garantir sua efetividade, não sendo tal exigência, portanto, uma peculiaridade real (natural) dos direitos sociais.

Ademais, Galdino (2005) vai além e descortina a retórica da falácia do exaurimento dos recursos orçamentários, denunciando que tal discurso visa alicerçar escolhas políticas que objetivam não tutelar efetivamente direitos fundamentais, a ver:

\footnotetext{
6 “A concepção canônica encontra apoio em um sistema normativo internacional; tem uma clara origem ideológica e se alicerça em argumentos técnico que exibem um grau de sofisticação nada depreciável. Um conjunto de "fontes” tão peculiar tem produzido efeitos importantes: A concepção canônica está fundamentada na teorização standart dos direitos humanos e é um estereótipo recorrente, não apenas nos âmbitos especializados, senão na maneira "popular" de visualizar e valorar os direitos humanos." Tradução nossa.

${ }^{7}$ Para alcançar tal empreitada, o autor se vale das análises perpetradas por HOLMES \& SUSTEIN (2000) em: The Cost of rights: Why liberty depends on taxes.
} 


\begin{abstract}
Deveras, ao dizer-se que o orçamento público não pode suportar determinada despesa, in casu, destinada a efetivação de direitos fundamentais, e tendo como parâmetro a noção de custos como óbices, quer-se necessariamente designar um orçamento determinado. Isso porque os recursos públicos são captados em caráter permanente - a captação não cessa nunca, de forma que, a rigor, nunca são completa mente exauridos. Assim sendo, nada obstaria a que um outro orçamento posterior assumisse a despesa em questão. Sem embargo dessa possibilidade muitos autores argumentam que esse meio - a exaustão da capacidade orçamentária - constitui um meio de frustrar a proteção dos direitos fundamentais. - O que usualmente frustra a efetivação de tal ou qual direito reconhecido como fundamental não é a exaustão de um determinado orçamento, mas sim a opção política (justa ou injusta, sindicável judicialmente ou não) de não se gastar dinheiro com aquele mesmo "direito". (Grifos do autor) (GALDINO, 2005, p. 234).
\end{abstract}

Com efeito, o ponto de chegada de Galdino (2005) para conclusão de que todos os direitos custam. Assim, seu pensamento coincide com o exame desenvolvido pela Sociologia Fiscal, a fim de compreender as relações entre o mercado capitalista e a política democrática, ressaltando que, segundo essa ótica, a política orçamentária revela o programa estatal com vistas efetividade ou não dos direitos humano-fundamentais.

\title{
3. AUSTERIDADE: UMA QUESTÃO DE ELEIÇÃO DE PRIORIDADES E A CONJUNTURA ATUAL
}

Ante os limites do presente trabalho, não se pretende exaurir a definição de austeridade. Entendemos aqui a austeridade como produto de um programa de governo, sendo esse um plexo de medidas jurídico-políticas que evidenciam a eleição de um modo de agir do Estado no que concerne a efetividade dos direitos sociais. Isso posto, a utilização do termo austeridade se coaduna com a perspectiva apresentada por Dweck (2018), no sentido de que o vocábulo austeridade exprime uma ideia de retidão e correção de conduta, adequação e responsabilidade.

A austeridade, tal qual aqui examinada, refere-se, portanto, ao modo de agir do Estado brasileiro no que concerne a tutela dos direitos sociais, que passa a realizar cortes no empenho do orçamento para tais áreas, bem como adota legislações que precarizam as relações de trabalho e pugnam pela reforma na previdência, ao passo que implementam o modelo liberal de mercado ${ }^{8}$. Assim, entendemos que a austeridade fiscal não pode ser examinada como algo estanque e atomizado, vez que conforma uma multiplicidade de postura estatais no que tange os direitos sociais, sendo um dos instrumentos de um programa de gestão de recursos e concessão de direitos.

\footnotetext{
${ }^{8}$ Nesse sentido a Medida Provisória no 881, de 30 DE ABRIL DE 2019, que instituiu o livre mercado no Brasil.
} 
Como já fora explicitado acima, todos os direitos custam e a alocação da receita revela as prioridades do Estado. Nesse sentido, convém observar que no texto da proposta de emenda à Constituição, que culminou na Emenda Constitucional no 95 de 2016 (marco normativo da austeridade no Brasil), nas oito páginas que conformam o documento, o vocábulo "crescimento" fora utilizado dezenove vezes, sendo esta a toada do agir estatal: o crescimento econômico, ainda que às custas, em sentido literal, dos direitos sociais.

Nesse sentido, a razão de ser do instituto, que realizou o maior corte no orçamento que, anteriormente, havia sido constitucionalmente destinado aos direitos sociais (mais especificamente saúde e educação), foi exatamente o crescimento econômico, uma vez que esse instrumento é primordial para o aquecimento da economia. Há, imbuída na defesa do crescimento econômico, a ideia de que o déficit orçamentário do Estado se deve aos direitos sociais, vez que, esses, por custarem em demasiado, comprometem todo o orçamento público. Além disso, como aponta Dweck (2018), há mais dois fundamentos para a austeridade, são eles: a fada da confiança e a metáfora do orçamento doméstico, todavia, estes também não resistem à confrontação.

Segundo Dweck (2018), a fada da confiança consiste no discurso de que, ao executar um ajuste fiscal enxugando os gastos com direitos sociais, obtendo superávit econômico, irá restabelecer a confiança dos investidores e por consequência haverá crescimento econômico, de modo que, se retomam os gastos com direitos sociais. Por sua vez, a metáfora do orçamento doméstico é a veiculação constante da comparação entre o orçamento doméstico e orçamento público. Partindo da premissa de que, para atingir o equilíbrio econômico e o crescimento, o Estado precisaria diminuir despesas, tal qual, as pessoas fazem na gestão individual de seus orçamentos domésticos.

Dweck (2018) afirma, ainda, que esses argumentos não se sustentam. No que tange à fada da confiança, tem-se que o setor privado não investe em razão do comportamento responsável do Estado, uma vez que, o setor privado investe na medida em que vislumbra o lucro, pouco se importando se o Estado tem se mostrado responsável na gestão dos seus recursos, ou seja, se a economia estatal tem mais déficit ou superávit. A decisão sobre investir ou não tem como diretriz o lucro do investidor, o que basicamente tem a ver com a demanda por seus produtos e serviços. Assim, não faz diferença para o investidor se a demanda pelos seus produtos e serviços decorre da seara pública ou privada.

Além disso, a retração dos gastos públicos durante a crise econômica pode conduzir a um ciclo de enfraquecimento da economia, produzindo exatamente o resultado oposto ao desejado com o corte de gastos, como explica Dweck (2018): 
Neste sentido, também é intuitivo pensar porque um ajuste fiscal não necessariamente melhora a confiança; um empresário não investe porque o governo fez ajuste fiscal, e sim quando há demanda por seus produtos e perspectivas de lucro. E, nesse ponto, a contração do gasto público em momentos de crise não aumenta a demanda, ao contrário, essa contração reduz a demanda no sistema. Em uma grave crise econômica, quando todos os elementos da demanda privada (o consumo das famílias, o investimento e a demanda externa) estão desacelerando, se o governo contrair a demanda pública, a crise se agrava. (DWECK, 2018, p. 20)

A metáfora do orçamento doméstico, por sua vez, também não se sustenta Dweck (2018). Dado que, comparar o orçamento doméstico ou a economia do governo é teratológico. Entre outras distinções essenciais, basta observar que: a) o governo determina seu próprio orçamento e cria sua receita e despesa, uma vez que decide onde e como alocará os recursos e como obterá receita, por meio da tributação por exemplo, enquanto que os indivíduos não controlam a receita que obtém; b) o gasto efetivado pelo governo retorna em tributos; c) o governo emite títulos de dívida, controla a taxa de juros e emite moeda. Assim, não há qualquer embasamento minimamente razoável para defender o corte de verbas para os direitos sociais, tendo como ponto de partida a comparação entre a gestão do orçamento público e do orçamento doméstico. Outro ponto que merece destaque, quanto ao exame do discurso que defende a austeridade, é a desconsideração de novas fontes de receita, por exemplo, por meio da criação do imposto sobre grandes fortunas ${ }^{9}$ de competência da União que jamais foi exercida.

Para Dweck (2018), são consequências da austeridade: a) diminuição da qualidade dos serviços públicos e consequente aumento demanda pelos serviços privados o que aumenta o lucro do setor privado; b) diminuição dos gastos com direitos sociais e consequente redução de tributos para o setor privado; c) aumento do desemprego provocado pela recessão econômica reduz pressões da classe trabalhadora e consequente precarização das relações de trabalho e consequente aumento do lucro ${ }^{10}$.

No caso do Brasil contemporâneo, o pacote de austeridade que teve início com a Emenda Constitucional $n^{\circ} 95$ de 2016, que desencadeou uma avalanche de propostas do governo federal, visando: reformar à previdência, contingenciar verba da educação, além de anúncios de revogação de normas de proteção e segurança no trabalho, e o fim de deduções no imposto de renda das despesas com educação e saúde privada. Essa é a conjuntura atual da austeridade no Brasil, sendo que todas essas medidas têm como fundamento a teria falaciosa de que os direitos sociais custam

\footnotetext{
${ }^{9} \mathrm{O}$ artigo 153 em seu inciso VII da Constituição Federal prevê que compete à União instituir impostos sobre grandes fortunas, nos termos de lei complementar.

${ }^{10}$ A Associação Nacional dos Procuradores do Trabalho (ANPT) e a Associação Nacional dos Magistrados da Justiça do Trabalho (Anamatra) divulgaram Nota Pública se manifestando contra a declaração do Presidente da República Jair Bolsonaro na qual fora anunciada a redução de $90 \%$ das Normas Regulamentadoras (NRs) de segurança e saúde no trabalho vigentes no país.
} 
demasiadamente, enquanto há outros direitos que são de graça, e que o arrocho nos gastos com direitos sociais implicará aumento da confiança e consequente crescimento econômico.

Noutro giro, essas medidas econômicas de austeridade vêm acompanhadas de um recrudescimento na participação popular e na autonomia das Universidades Públicas Federais e das Agências Reguladoras. O Decreto no 9.759, de 11 de abril de 2019, definiu que a partir de 28 de junho de 2019 ficam extintos diversos órgãos colegiados que compõem o Governo Federal. O Decreto n ${ }^{\circ}$ 9.794, de 14 de maio de 2019, instituiu o Sistema Integrado de Nomeações e Consultas (SINC), órgão que efetivará a intermediação entre a Casa Civil e Presidência da República e a nomeação de dirigentes, incluídas os cargos e funções das agências reguladoras e das instituições federais de ensino superior.

As medidas adotadas pelo governo desde a EC no 95 de 2016 conformam um regime de austeridade no plano econômico e indicam recrudescimento da participação popular nas decisões governamentais, implementada pela extinção dos órgãos colegiados, e enfraquecimento da autonomia das instituições públicas de ensino superior federais e das agências reguladoras. Desse modo, a conjuntura atual do Brasil, que une austeridade e retrocesso nas estruturas que engendram a democracia, conferem mais importância a estudos como os realizados por Galofré-Vilà, Meissner, McKee, e Stuckler, dentre outros, os quais indicam que a austeridade adotada pela Alemanha, em 1930, pode ter tido um papel importante na ascensão do Nazismo, como informa Matthews (2019), uma vez que o estudo relevou uma relação entre os estados e distritos que mais foram afetados pela austeridade da gestão que antecedeu o nazismo foram justamente aquelas nas quais o nazismo obteve maior adesão. Assim, uma vez apresentada a estrutura na qual o discurso que defende a austeridade se pauta, bem como as possíveis relações entre o excesso de austeridade e retrocesso democrático, passa-se ao exame dos efeitos da austeridade nas assimetrias de gênero.

\section{AUSTERIDADE: UMA MEDIDA MACHISTA E RACISTA}

As medidas de austeridade exigem cortes de gastos e desmantelamento de instituições públicas que afetam diretamente os programas sociais, portanto, as populações vulneráveis que dependem deles, como as mulheres. A sociedade brasileira é historicamente marcada por uma hierarquização entre homens e mulheres, que estabelece configurações capazes de colocá-las em uma posição de desvantagem. Assim, a austeridade fiscal se insere em um contexto social desfavorável para elas e tem-se mostrado capaz de aprofundar essas assimetrias. Para Crenshaw (2002), a realidade das mulheres deve ser analisada sob uma perspectiva interseccional, que leve em consideração gênero, raça e classe. 


\begin{abstract}
A interseccionalidade é uma conceituação do problema que busca capturar as consequências estruturais e dinâmicas da interação entre dois ou mais eixos da subordinação. Ela trata especificamente da forma pela qual o racismo, o patriarcalismo, a opressão de classe e outros sistemas discriminatórios criam desigualdades básicas que estruturam as posições relativas de mulheres, raças, etnias, classes e outras. Além disso, a interseccionalidade trata da forma como ações e políticas específicas geram opressões que fluem ao longo de tais eixos, constituindo aspectos dinâmicos ou ativos do desempoderamento. (CRENSHAW, 2002, p. 177)
\end{abstract}

A sociedade, então, estaria estruturada como uma pirâmide. No topo dos privilégios, encontram-se homens brancos, seguidos por mulheres brancas, logo abaixo, homens negros e, na base da pirâmide, as mulheres negras. Desse modo, as mulheres negras são oprimidas tanto por homens (brancos e negros) quanto por mulheres brancas. Essa estrutura social pode ser observada com clareza no contexto brasileiro quando analisamos os dados do IPEA - Instituto de Pesquisa Econômica Aplicada.

O Retrato das Desigualdades de Gênero e Raça - 1995-2015 ${ }^{11}$, realizado pelo IPEA, demonstra que a participação feminina no mercado de trabalho formal, nesse período de 20 anos, variou entre $54-55 \%$, já a participação masculina alcançou índices de $85 \%$. Os dados da pesquisa deixam claro as raízes da divisão sexual do trabalho, que "é uma base fundamental sobre a qual se assentam hierarquias de gênero na sociedade contemporânea.” (BIROLI, 2018, p. 23). A pesquisa compara esses índices aos dados da educação e evidencia que, nesse último quesito, as mulheres encontram-se em condição superior à dos homens, no entanto, essa representatividade não se reflete no mercado de trabalho, ressaltando uma dificuldade das mulheres conseguirem uma posição no mercado formal. Há de se observar aqui, também, um viés racista, uma vez que, em 2015, apenas 4,9\% das mulheres brancas com mais de 15 eram analfabetas, já para as mulheres negras, esse número chega a 10,2\%, considerando mesma faixa etária e o mesmo período, ficando na base da pirâmide.

Outro destaque da pesquisa é o trabalho doméstico, que mais uma vez ressalta o viés racista e machista da estrutura social brasileira. Em 2015, 18\% das mulheres negras dedicam-se ao trabalho doméstico remunerado, enquanto que para mulheres brancas essa porcentagem cai para $10 \%{ }^{12}$. Assim, ainda que o trabalho doméstico seja remunerado, a participação feminina na execução dessas tarefas é majoritária, reafirmando a divisão sexual e racial do trabalho. Esses dados são apenas para ilustrar um dos muitos pontos que colocam as mulheres em condições piores que as dos homens, o intuito do exemplo não é o de exaurir o tema, mas apenas elucidar. Muitas

\footnotetext{
11 http: / $/$ www.ipea.gov.br/portal/index.php?option=com content\&view=article\&id $=29526$.

12 http: / $/$ www.ipea.gov.br/portal $/$ index.php?option $=$ com content\&view $=$ article\&id $=29526$.
} 
desvantagens são enfrentadas por elas no mercado de trabalho e fora dele. Sofrem diversas formas de discriminação e violência, portanto, carecem de ações do poder público no intuito de dirimir essas assimetrias.

A austeridade tem se mostrado um retrocesso para a proteção dos direitos das mulheres. Dentre suas medidas, observamos a destruição de instituições promotoras da paridade de gênero. Em 2003, foi criada a Secretaria de Políticas para as mulheres (SPM), como ministério diretamente ligado à Presidência. Em 2015, Ministérios incumbidos de zelar pelos direitos humanos, paridade racial e equidade de gênero foram mesclados em um único Ministério, fora da estrutura direta da Presidência. Em 2016, esse Ministério passou a fazer parte do Ministério da Justiça e Cidadania. Em 2017, a SPM voltou para a Secretaria do Governo da Presidência, porém, com perda expressiva de cargos e status (Brasil: Direitos Humanos em Tempos de Austeridade) ${ }^{13}$. Essas ações, representam uma diminuição do poder de atuação dessas entidades governamentais.

O enfraquecimento e desmantelamento das instituições que zelam pela promoção da paridade de gênero, nesse momento, vem acompanhado de cortes de verbas. Se compararmos à previsão orçamentária de 2014 e de 2018, percebemos que os cortes, em valores reais, foram substanciais. Em 2014, o Programa de Políticas para as Mulheres: promoção e enfrentamento à violência contava com um orçamento de R \$ 147.194.447, já em 2018 (dois anos após a implementação do pacote de austeridade), a verba passou para $R \$ 24.774 .650$, o que corresponde a uma queda de 83\%. A dotação orçamentaria do Programa da Igualdade Racial e Superação do Racismo, no mesmo período, passou de $\mathrm{R} \$ 58.008 .750$ para $\mathrm{R} \$ 1$ 16.621.023; o que representa um corte de $71,3 \%{ }^{14}$. A restrição de recursos financeiros acompanhada do esgotamento dessas instituições e programas específicos geram uma perda de instrumento de combate às violências de gênero. Além de evidenciar o viés machista e racista das medidas.

Em abril de 2018, o então presidente Michel Temer, às vésperas de uma eleição presidencial, realocou mais R \$ 200 milhões para a Secretaria de Comunicação da Presidência (SECON) ${ }^{15}$. Parte do dinheiro destinava-se ao programa de combate à violência contra a mulher e foi transferido para SECON para cobrir gastos com publicidade. Mais uma medida que afeta negativamente as mulheres, e que opta por publicidade em detrimento da vida das delas. O Brasil está em quinto lugar no ranking mundial de países que mais vitimam mulheres, metade desses homicídios tiveram familiares como autores (Dossiê Feminicídio, 2017) ${ }^{16}$. O Atlas da Violência $2018^{17}$ analisou o

\footnotetext{
${ }^{13}$ https://www.oxfam.org.br/sites/default/files/arquivos/Fact Sheet 2 Portugues V-Print 2.pdf.

${ }^{14} \mathrm{http} / / /$ brasildebate.com.br/wp-content/uploads/DOC-AUSTERIDADE doc3- L9.pdf.

15 https://revistaforum.com.br/politica/temer-retira-dinheiro-do-combate-a-violencia-contra-a-mulher-para-usarem-publicidade/.

${ }^{16}$ https://dossies.agenciapatriciagalvao.org.br/feminicidio/capitulos/qual-a-dimensao-do-problema-no-brasil/.

${ }^{17}$ http: $/ /$ www.ipea.gov.br/portal/index.php?option $=\mathrm{com}$ content\&view=article\&id=33410\&Itemid $=432$.
} 
período de 2006 à 2016 e aponta um aumento de homicídios contra as mulheres que variou de 4,5\% para 6,4\% (homicídios para cada cem mil brasileiras). $O$ índice entre mulheres negras teve um aumento de $15,4 \%$, enquanto que para mulheres brancas apresentou uma queda de $8 \%$.

Os números deixam claro o lugar de vulnerabilidade e subalternidade que as mulheres, em especial as mulheres negras, ocupam na sociedade. Assim, corte de verba para programas que buscam a promoção da paridade de gênero, mostra-se uma ameaça aos direitos de todas as mulheres. Os índices de morte de mulheres são expressivos e especialmente alarmantes para a população negra, mesmo com a atuação estatal. As medidas de austeridade promovem o enfraquecimento das instituições e cortes enérgicos, suas consequências, ao que tudo indica, serão o aumento de homicídios, especialmente para mulheres negras. São medidas que atingem diretamente as mulheres. "Momentos como o atual, de austeridade fiscal, são momentos de reafirmação dessa hierarquia: o lado dominado por homens se impõe ao lado dominado por mulheres.” (Austeridade e Retrocesso: Impactos Sociais da Política Fiscal no Brasil, 2018 p. 51) ${ }^{18}$. A austeridade fiscal no Brasil reafirma e intensifica os ideais de supremacia masculina e supremacia branca, historicamente presentes na sociedade brasileira.

\section{CONSIDERAÇÕES FINAIS}

Pela perspectiva da Sociologia Fiscal, economia, política fiscal e sociologia devem ser observadas de forma conjunta, uma vez que se influenciam mutuamente (BACKHAUS, 2002). Assim, é fundamental analisar os impactos sociais da austeridade fiscal adotada no Brasil, com e Emenda Constitucional n 95 de 2016, que tem como escopo promover o crescimento econômico. Especialmente pelo fato de que o pacote da austeridade exige ajuste fiscal e contenção de gastos com programas sociais, o que faz com que os arranjos e realocações se investimentos sejam intensificados. Esses arranjos nem sempre priorizam as políticas sociais. Acontece que mulheres, por serem um grupo vulnerável, carecem dessas políticas.

Ao reduzir os gastos com os programas sociais, o governo gera uma sobrecarga para as mulheres. Elas são culturalmente responsáveis pelo trabalho do cuidado de crianças e idosos. A fragilização de serviços como educação, saúde e previdência social faz com que toda essa demanda recai sobre elas, que já executam uma jornada dupla de trabalho, privando-as de recursos financeiros e tempo. Outra consequência importante da austeridade, é o aumento do desemprego. Mulheres enfrentam dificuldades para ingressar no mercado de trabalho, portanto, são fortemente atingidas pela baixa oferta de emprego. No primeiro trimestre de 2017 , a taxa de desocupação de

\footnotetext{
${ }^{18}$ http://brasildebate.com.br/wp-content/uploads/DOC-AUSTERIDADE doc3- L9.pdf.
} 
mulheres era de 50,6\%, dentre elas, as negras com 63,2\%. Para além dessas consequências, o governo promoveu cortes diretos e significativos em programas específicos para a proteção da violência contra a mulher e superação do racismo. Os impactos dessas medidas afetam as mulheres, em particular as mulheres negras, mostrando a face machista e racista do governo.

\section{REFERÊNCIAS}

AGÊNCIA PATRÍCIA GALVÃO. (2017). Por que as taxas brasileiras são alarmantes. Disponível em: $<$ https://dossies.agenciapatriciagalvao.org.br/feminicidio/capitulos/qual-a-dimensao-doproblema-no-brasil/>. Acesso em: 04.mai,2019.

BACKHAUS, J. G. (2002). Fiscal Sociology: what for? In: BACKHAUS, J., WAGNER, R. (eds). Handbook of Public Finance. Londres: Springer.

BIROLI, F. M. (2018). Gênero e Desigualdades limites da democracia no Brasil. $1^{a}$ edição. São Paulo: Boitempo.

BOBBIO, N. (2004). A era dos direitos. Nova ed., $7^{\mathrm{a}}$ reimpressão. Rio de Janeiro: Elsevier.

BRASIL. (1988). Constituição da República Federativa do Brasil de 1988. Brasília, DF: Presidência da República. Disponível em: http://www.planalto.gov.br/ccivil_03/Constituicao/ Constituiçao.htm. Acesso em: 5.fev. 2019.

BRASIL. (2019a). Decreto $\mathrm{n}^{\circ}$ 9.741, de 29 de março de 2019. Disponível em: $<$ http://www.in.gov.br/materia/-

/asset_publisher/Kujrw0TZC2Mb/content/id/69237336/do1e-2019-03-29-decreto-n-9-741-de29-de-marco-de-2019-69237302> Acesso em: 3.abr.2019.

BRASIL. (2019b). Decreto $\mathrm{n}^{\circ}$ 9.759, de 11 de abril de 2019. Disponível em: <http://www.planalto.gov.br/ccivil_03/_ato2019-2022/2019/decreto/D9759.htm>. Acesso em: 20.abr.2019.

BRASIL. (2019c). Decreto $\mathrm{n}^{\circ}$ 9.794, de 14 de maio de 2019. Disponível em: <http://www.planalto.gov.br/ccivil_03/_ato2019-2022/2019/decreto/D9794.htm>. Acesso em: 20.mai.2019.

BRASIL. (2016a). Emenda Constitucional no 95, de 15 de dezembro de 2016. Disponível em: <http://www.planalto.gov.br/ccivil_03/Constituicao/Emendas/Emc/emc95.htm Acesso em: 7.fev.2019.

BRASIL. (2016b). Proposta de emenda constitucional. Disponível em: $<$ https://www.camara.leg.br/proposicoesWeb/prop_mostrarintegra;jsessionid=09DA93B91D0 C4B92995C5DEB48609DF1.proposicoesWebExterno2?codteor $=1468431 \&$ filename $=\mathrm{PEC}+241$ /2016>. Acesso em: 10.mai.2019. 
CORREIA NETO, C. de B. (2018). Os tributos e os direitos fundamentais: limites, objetivos e instrumentos. In: NOVELINO, M., FELLET, A. Separação de Poderes: aspectos contemporâneos da relação entre Executivo, Legislativo e Judiciário. Salvador: Juspodivm.

CRENSHAW, K. (2002). Documento para o encontro de especialistas em aspectos da discriminação racial relativos ao gênero. Revista de estudos feministas, vol. 10, n 1, p. 171-188.

DHESCA BRASIL. (2017). O Impacto da Politica Econômica de Austeridade nos Direitos Humanos. Disponível em:

$<$ https://br.boell.org/sites/default/files/publicacao_dhesca_preliminar_2_baixa.pdf $>$. Acesso em: 20.fev.2019.

DWECK, E., OLIVEIRA, A. L. M. de, ROSSI, P. (Orgs). (2018). Austeridade e retrocesso: impactos sociais da política fiscal no Brasil. São Paulo: Brasil Debate; Fundação Friedrich Ebert.

GALDINO, F. (2005). Introdução à teoria dos custos dos direitos: os direitos não nascem em árvores. Rio de Janeiro: Lumen Juris.

GENSCHEL, P., SCHWARZ, P. (2012). Tax Competition and Fiscal Democracy. TranState working papers, $\mathrm{n}^{\circ} .161$, p. 1-22.

GOLDSCHEID, R. (1958). A Sociological Approach to Problems of Public Finance. In: MUSGRAVE, R. A., PEACOCK, A. T. (Eds.). Classics in the Theory of Public Finance. Londres: MacMillan.

HOLMES, S., SUSTEIN, C. R. (2000). The Cost of rights: Why liberty depends on taxes. New York: Norton.

INESC., CESR., OXFAM BRASIL. (2018). Monitoramento dos direitos humanos em tempos de austeridade no Brasil. Disponível em: < https://www.inesc.org.br/wpcontent/uploads/2018/08/Rel_Dir_Hum_Temp_Aust-NOVO-1-_V3.pdf?x31288> Acesso em: 5.mai.2019.

IPEA. (2018). Atlas da Violência 2018. Disponível em: <http://www.ipea.gov.br/portal/images/stories/PDFs/relatorio_institucional/180604_atlas_da _violencia_2018.pdf>. Acesso em: 20.fev.2019.

IPEA. (2016). Mulheres e Trabalho: breve análise do periodo 2004-2014. Disponível em: <http://www.ipea.gov.br/portal/images/stories/PDFs/nota_tecnica/160309_nt_24_mulher_tr abalho_marco_2016.pdf> Acesso em: 3.mai.2019.

IPEA. (2011). Retrato das desigualdades de gênero e raça. Disponível em: <http://www.ipea.gov.br/retrato/> Acesso em: 20.fev.2019.

IPEA. (2017). Retrato das desigualdades de gênero e raça - 1995 a 2015. Disponível em <http://www.ipea.gov.br/portal/images/stories/PDFs/170306_retrato_das_desigualdades_de_ genero_raca.pdf $>$ Acesso em: 20.fev.2019. 
MACHADO, H. de B. (2010). Curso de Direito Tributário. São Paulo: Malheiros.

OXFAM BRASIL. (2017). Brasil: direitos humanos em tempos de austeridade. Disponível em: $<$ file://C:/Users/Felipe/Downloads/Fact_Sheet_2_Portugues_V_digital_2.pdf $>$. Acesso em: 05.mar.2019.

RABOSSI, E. (1993). Los derechos humanos básicos y los errores de la concepción canónica. Revista del Instituto Interamericano de Derechos Humanos, $n^{\circ} 18$, p. 45-73.

RIBEIRO, R. L. (2008). Direito tributário brasileiro: parte geral. Goiânia: Kelps.

SCOTT, J. W. (1995). Gênero: uma categoria útil de análise histórica. Educação \& Realidade, vol. 20, $\mathrm{n}^{\mathrm{o}} 2, \mathrm{p} .71-99$.

SCHUMPETER, J. A. (1991). The Crisis of the Tax State. In: SWEDBERG, R. (Org.) The economics and sociology of capitalism. Princeton: Princeton University Press.

SIGA BRASIL. (2017). Portal do Orçamento Federal - Senado Federal. Disponível em: <https:// www12.senado.leg.br/orcamento/sigabrasil> Acesso em: 13.fev.2019.

STREECK, W. (2011). The crises of democratic capitalism. New Left Review, n 71, p. 5-29. 